\title{
Relationship Analysis between Body Shape and Physical Ability based on the Least Squares
}

\author{
Yang Jinyan, Li Yu, Zou Qiyang \\ Physical Teaching Room \\ Dalian Navy Academy, Dalian, China \\ xxxggglll0@163.com
}

\author{
Xu Guanlei \\ Meteorological Teaching Room of Ocean Department \\ Dalian Navy Academy, Dalian, China \\ xgl_86@163.com
}

\begin{abstract}
In physical teaching and physical training, the physical ability is the base and is of much importance in physical education. Teachers can adopt appropriate physical teaching and physical training scheme if they know the students' physical ability exactly. This paper proposes a method to analyze the relationship between body shape and physical ability based on the least squares. That is to say, the relation model is built up based on lots of data of students' body shapes and physical abilities through the least squares. Via this relation model, we can estimate the student's physical ability given the body shape. Thus, the student will be trained and taught by the appropriate manner. Finally, experiments are given to show the efficiency of this proposed me thod in this paper.
\end{abstract}

Keywords_least squares method (LSM); physical ability; body shape; physical teaching and training

\section{INTRODUCTION}

Ministry of education ordains that all kinds of aged students should have different physical diathesis in different ages [1]. This kind of physical diathesis mainly contains the sport ability. The so called sport ability is mainly the physical ability. Different people have different understanding for the physical ability in different places [1]-3]. Up till now, there has been no uniformed concept of physical ability [4]-[9]. Generally speaking, the physical ability has the following explains: (1) the sport ability shown through the cooperation of all kinds of organs for the students; (2) the athletes' ability shown in the sports; (3) the whole ability of students in all kinds of sports and actions [4-6]. For the military students, it is also very different in the understanding of physical ability. Especially, under the cases of complicated and high tech war setting, the physical ability is not only a physical element of bodies, and it also includes the whole ability to finish all kinds of military tasks. Or to say, the physical ability is the ability to vanquish the enemies in all kinds of backgrounds. Therefore, the physical abilities are three folds: (1) the physical ability has relations with sport elements; (2) the physical ability has relations with adaptability; (3) the physical ability has relations with psychology. In a word, good military physical ability is the element of military students and is also the base of future victory [6-9].

Therefore, in order to make better physical teaching and physical training for the military students, this paper proposes a new method to analyze the relationship between body shape (see Fig.1 and Fig.2 for some examples of body shapes of male and female students [10]) and physical ability based on the least squares. Or to say, the relation model is built up based on lots of data of students' body shapes and physical abilities through the least squares [5]. Via this relation model, we can estimate the student's physical ability given the body shape. Finally, the student will be trained and taught by the appropriate manner.

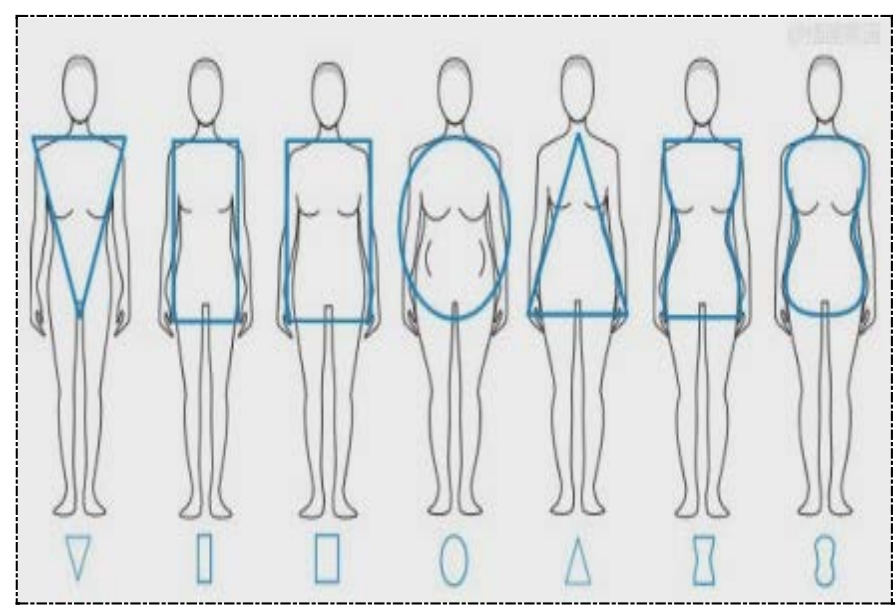

Fig. 1. Some body shapes of female students in contours.

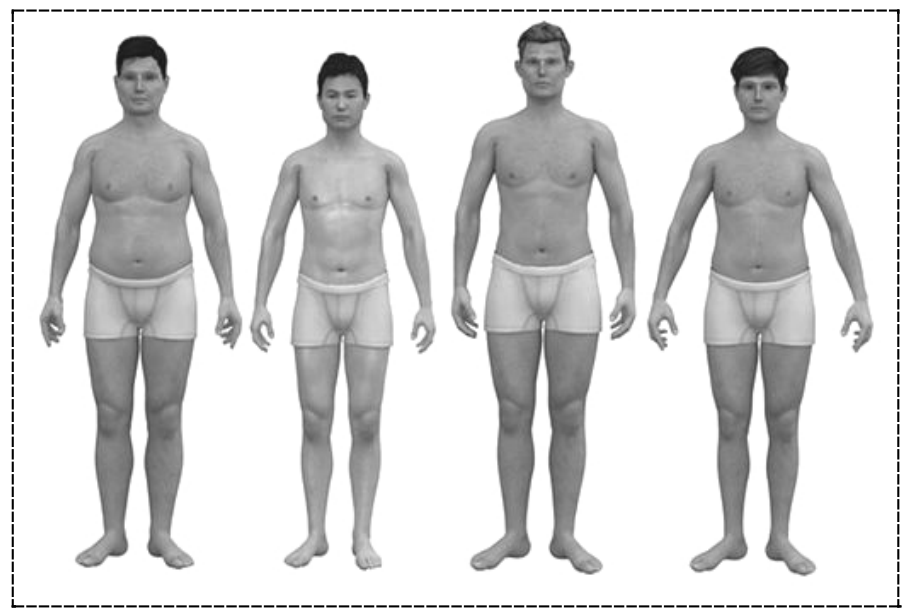

Fig. 2. Some body shapes of male students in simulation.

This work is sponsored by the NSFCs (61471412, 61771020). 


\section{The Least Squares and Building of ModeL}

\section{A. The Least Squares}

In scientific experiments and statistical problems, people often strive to obtain an analytic relation function $y=\varphi(x)$ through the given data between the two variables $x$ and $y$ [5]. That is to say, through the given data of $N$ points $\left(x_{i}, y_{i}\right),(i=1,2 \ldots N)$, how can we get the regression of these variables. The regression is very different from the interpolation. The regression is to find the most approximate function to denote these data, but not interpolate these data in every point. Among all these methods, the least squares method is the most widely used one. For example, for the date point $\left(x_{i}, y_{i}\right)$, set $y_{i}^{*}=a+b x_{i}$, we can obtain the linear regression that represents all the data in the least error.

The error is defined as:

$$
\delta_{i}=y_{i}-y_{i}^{*}=y_{i}-a-b x_{i}
$$

The error in equation (1) can be used for the performance estimation of parameters $a$ and $b$. There are many methods to measure the performance of this function, among which the least squares method is the most widely used one, i.e.,

$$
Q=\sum_{i=1}^{N} \delta_{i}^{2}
$$

Furthermore, we set

$$
S(a, b)=Q=\sum_{i=1}^{N}\left[y_{i}-\left(a+b x_{i}\right)\right]^{2}
$$

For the extreme, we can have the following equations for the two parameters $a$ and $b$ :

$$
\begin{aligned}
& \frac{\partial S}{\partial a}=-2 \sum_{i=1}^{N}\left(y_{i}-a-b x_{i}\right)=0 \\
& \frac{\partial S}{\partial b}=-2 \sum_{i=1}^{N} x_{i}\left(y_{i}-a-b x_{i}\right)=0
\end{aligned}
$$

Finally, resolve the above two equations, we can obtain the two parameters $a$ and $b$ as follows:

$$
\left\{\begin{array}{l}
a=\bar{y}-b \bar{x} \\
b=\frac{\sum_{i=1}^{N}\left(x_{i}-\bar{x}\right)\left(y_{i}-\bar{y}\right)}{\sum_{i=1}^{N}\left(x_{i}-\bar{x}\right)^{2}},
\end{array}\right.
$$

where $\bar{x}$ and $\bar{y}$ respectively denote the means:

$$
\bar{x}=\frac{1}{N} \sum_{i=1}^{N} x_{i}, \bar{y}=\frac{1}{N} \sum_{i=1}^{N} y_{i} .
$$

In the same manner, for the data $x=x_{1}, x_{2}, \cdots x_{n}$ and $y=y_{1}, y_{2}, \cdots y_{n}$, we use $\varphi(x)$ for the relation function: $y=f(x)$, then $\varphi(x)$ can be represented as the morder polynomial. We also know that every function can be represented as a polynomial, i.e.:

$y=f(x) \approx \varphi_{m}(x)=a_{0}+a_{1} x+a_{2} x^{2}+\cdots+a_{m} x^{m}=\sum_{i=0}^{m} a_{i} x^{i}$.
In using the least squares method, we must satisfy the condition: minimizing the equation $Q_{m}=\sum_{j=1}^{n}\left(\varphi_{m}\left(x_{j}\right)-y_{j}\right)^{2}$ to obtain the function $f(x)$ for the regression model.

For the multi-variables, we have

$$
\left\{\begin{array}{l}
v(1)=a(0)+a(1) c(1)+a(2) c(1)^{2}+\cdots+a(n) c(1)^{n} \\
v(2)=a(0)+a(1) c(2)+a(2) c(2)^{2}+\cdots+a(n) c(2)^{n} \\
\vdots \\
v(n)=a(0)+a(1) c(n)+a(2) c(n)^{2}+\cdots+a(n) c(n)^{n}
\end{array}\right.
$$

Set

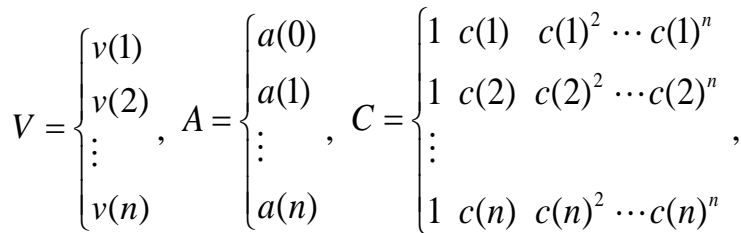

Finally, we obtain the resolution of the optimization of LQM:

$$
A=\left(C \cdot C^{T}\right)^{-1} C^{T} \cdot V .
$$

\section{B. Building of Model}

First, we must determine the parameters of body shape. The main features of body shape are defined as follows in the aspects of weight, height, thinness and fatness and so on. They can be defined as four folds: body length, body width, body perimeter and body corporeity. On the other hand, the body mainly includes three types: thin-long, Stout and motile. Thinlong means that the student will be relatively long. Thin-long mainly includes the height at seating and standing, the length of arms and legs. If the student is thin (fat) and short (long), then he/she will be relatively stout. Stout mainly includes the ratio of height at standing and seating, the length of arms and legs and including width of waist, width of shoulders, width of antrum, width of head and so on. Motile is a relatively concept because if the student is thin (fat) and very short, then he/she will be relatively motile. Motile mainly includes the ratio of height at standing and seating, the length of arms and legs and including width of head, width of waist, width of shoulders, width of antrum and so on. In order to use the two-order least squares method, we let

$$
\begin{aligned}
& \text { body shaper }=w_{1} \cdot \text { body lenghth }+w_{2} \cdot \text { body width } \\
& +w_{3} \cdot \text { body perimeter }+w_{4} \cdot \text { body corporeity }
\end{aligned}
$$

where $w_{1}, w_{2}, w_{3}, w_{4}$ are four weights for the balance of these parameters.

Second, we must determine the parameters of the physical ability. The main features of the physical abilities are three folds: (1) the ability of sports; (2) the ability of adaptability; (3) the ability in psychology. In order to use the two-order least squares method, we let

$$
\begin{aligned}
& \text { physical ability }=w_{01} \cdot \text { sport }+w_{02} \cdot \text { adaptability } \\
& +w_{03} \cdot \text { psychology }
\end{aligned}
$$


where $w_{01}, w_{02}, w_{03}$ are four weights for the balance of these parameters.

Finally, we can use the two-order least squares method to build up the model as follows:

$$
y=a x^{2}+b x+c
$$

where $a, b, c$ are the determined parameters by the least squares method. The examples can be found in fig. 3 and Fig. 4. Note that all these data are normalized to the interval of $[0,1]$.

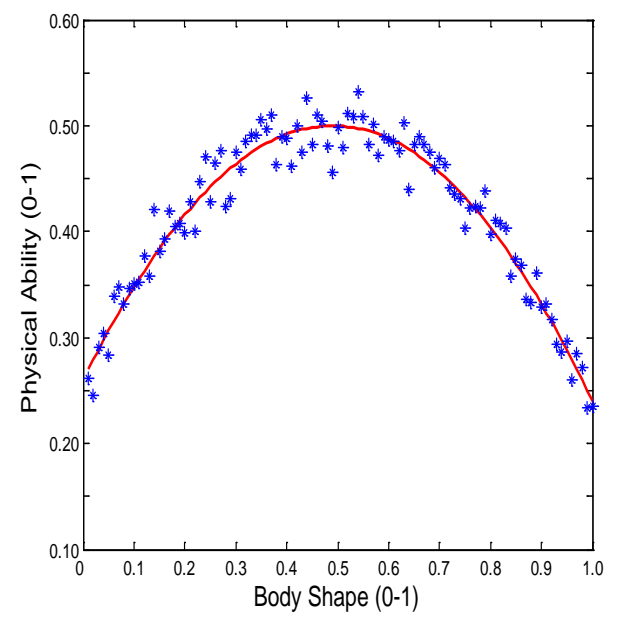

Fig. 3. The relationship between body shape and physical ability by LSM for male students.

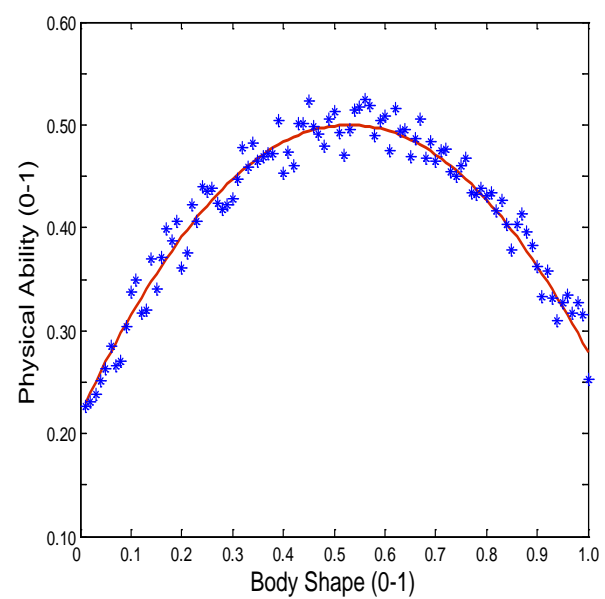

Fig. 4. The relationship between body shape and physical ability by LSM for female students.

We find that can obtain the ideal regression results by the least squares method for the male and female students.

The parts of data can found in TABLE I.
TABLE I. THE PART SOF DAT A OF BODY SHAPE AND PHYSICAL ABILITY

\begin{tabular}{|c|c|}
\hline Body Shape & Physical Ability \\
\hline 0.15 & 0.2566 \\
\hline 0.16 & 0.2858 \\
\hline 0.17 & 0.3118 \\
\hline 0.18 & 0.2931 \\
\hline 0.19 & 0.3574 \\
\hline 0.22 & 0.3951 \\
\hline 0.35 & 0.4952 \\
\hline 0.34 & 0.4790 \\
\hline 0.37 & 0.4812 \\
\hline 0.50 & 0.5176 \\
\hline 0.61 & 0.4342 \\
\hline 0.65 & 0.4114 \\
\hline 0.69 & 0.3626 \\
\hline 0.78 & 0.3338 \\
\hline 0.80 & 0.3780 \\
\hline 0.81 & 0.3115 \\
\hline 0.98 & 0.2623 \\
\hline$\ldots \ldots$. & $\ldots . .$. \\
\hline
\end{tabular}

\section{EXPERIMENTS}

After the building of the model, in order to test the efficiency of the method, we use some real data to measure the performance (see table 1 and table 2 ).

TABLE II. THE TEST FOR THE MALE STUDENTS

\begin{tabular}{|c|c|c|c|}
\hline $\begin{array}{c}\text { Student } \\
\text { numbers }\end{array}$ & $\begin{array}{c}\text { Tested } \\
\text { number }\end{array}$ & $\begin{array}{c}\text { Correct } \\
\text { numbers }\end{array}$ & $\begin{array}{c}\text { Precision } \\
\text { rate }\end{array}$ \\
\hline Grade 1 & 100 & 82 & $82 \%$ \\
\hline Grade 2 & 100 & 85 & $85 \%$ \\
\hline Grade 3 & 100 & 86 & $86 \%$ \\
\hline Grade 4 & 100 & 89 & $89 \%$ \\
\hline Total & 400 & 342 & $85.5 \%$ \\
\hline
\end{tabular}

TABLE III. THE TEST FOR THE FEMALE STUDENTS

\begin{tabular}{|c|c|c|c|}
\hline Student numbers & Tested number & Correct numbers & $\begin{array}{c}\text { Precision } \\
\text { rate }\end{array}$ \\
\hline Grade 1 & 50 & 40 & $80 \%$ \\
\hline Grade 2 & 50 & 44 & $84 \%$ \\
\hline Grade 3 & 50 & 41 & $82 \%$ \\
\hline Grade 4 & 50 & 45 & $90 \%$ \\
\hline Total & 200 & 342 & $85.0 \%$ \\
\hline
\end{tabular}

In table 1, we employ 100 male students from every grade and use the model to estimate their physical ability based on their body shapes. In table 2, we employ 50 female students from every grade and use the model to estimate their physical ability based on their body shapes. Finally, the total precision rate reaches $85.5 \%$ and $85.0 \%$ respectively for the male students and female students. This result proves that our method is efficient.

\section{CONCLUSIONS}

In physical teaching and physical training, the physical ability is the elementary base and is of much importance to physical education. Teachers often adopt appropriate physical 
teaching and physical training scheme if they know the students' physical ability in advance. In this paper we proposed a method to analyze the relationship between body shape and physical ability based on the least squares method. First, the relation model is built up based on lots of data of students' body shapes and physical abilities through the least squares. Second, via this relation model, we can estimate the student's physical ability given the body shape. Thirdly, the student will be trained and taught by the appropriate manner. Finally, some experiments are given to show the efficiency of the proposed method. In the future work we will use more methods to analyze this topic.

\section{ACKNOWLEDGMENT}

We will thank the anonymous college students in our classroom for their cooperation with our experiments.

\section{REFERENCES}

[1] Zhang Yongning. Meteorology for Mariners, Dalian Marine University Press, Dalian, 2008.

[2] Yang Jinyan, Xu Guanlei, Li Yu, Zou Qiyang. College Student Classification in Swimming Teaching and Training[C]. Advances in
Social Science, Education and Humanities Research (ASSEHR), volume 75:7-10.

[3] Xu Guanlei, Shao Limin, Liu Yonglu, Lang Fengwang. The Content Classification via Bayesian Model in Meteorological Teaching [C]. Advances in Social Science, Education and Humanities Research (ASSEHR), volume 75:11-14.

[4] Kircaldy B.D. Gender and personality determinants of recreational interests [J],Studia Psychological,1990(32): 115-121.

[5] R. O. Duda, P. E. Hart, and D. G. Stork. Pattern Classification. Willey and Sons, Inc., New York, 2nd edition, 2001.

[6] Liang xiao Jiang, Dianhong Wang, Zhihua Cai, Xuesong Yan, Survey of Improving Naive Bayes for Classification, Advanced Data Mining and Applications, Volume 4632 of the series Lecture Notes in Computer Science, 2007, pp 134-145.

[7] R. Chellappa and S. Chatterjee, "Classification of textures using Gaussian Markov random fields,” IEEE Trans. Acoust., Speech, Signal Process., vol. ASSP-33, no. 4, pp. 959-963, Apr. 1985.

[8] Kusluvan,S. \& Kusluvan,Z. Percetions and attitudes of undergraduate tourism students towards working in the touris m industry in Turkey [J].Tourism Management,2000(21):251 -269.

[9] Diener,E,Larsen,R. J \& Emmons,R. A. Perso Situation interactions: Choice of situations and congruence response modtls[J] Journal of Personality and Social Psychology,1984(47): 580-592.

[10] http://news.sina.com.cn/w/p/2013-10-16/151928450393.shtml and https://www.duitang.com/blog/?id=58207795 